\title{
A description of the volume and intensity of sporadic physical activity among adults
}

\author{
Jordan Robson ${ }^{1}$ and lan Janssen ${ }^{1,2^{*}}$
}

\begin{abstract}
Background: Emerging evidence indicates that accumulating physical activity in periods of less than 10 minutes, termed sporadic physical activity (SPA), has similar effects on health as a similar volume of bouted physical activity (BPA). The purpose of this study was to describe the volume and intensity of SPA in adults.

Methods: Participants consisted of a representative sample of 6040 adults aged 20 years and older from the 2003-2006 U.S. National Health and Examination Nutrition Survey. Physical activity was measured over 7 days using Actigraph AM-7164 accelerometers. Each minute of accelerometer data was initially categorized by intensity (sedentary, light, moderate-to-vigorous), and then non-sedentary time was categorized as following a BPA or SPA pattern ( $\geq$ or $<10$ consecutive minutes).

Results: American adults accumulated 103 minutes/day of SPA of an intensity, which represented 27\% of their total (BPA + SPA) daily physical activity. Only 3 minutes/day of the SPA was of a moderate-to-vigorous intensity; however, participants accumulated 16 minutes/day of moderate-to-vigorous activity embedded within light intensity BPA. This embedded moderate-to-vigorous activity represented 85\% of total daily moderate-to-vigorous activity.

Conclusions: SPA accounted for about a quarter of total daily physical activity. While the amount of moderate-tovigorous SPA was minimal, a significant amount of moderate-to-vigorous activity was accumulated within bouts of primarily light intensity activity.
\end{abstract}

Keywords: Motor activity, Health surveys, Adult

\section{Background}

Physical inactivity is common in the modern Western lifestyle [1], where it plays a role in the development of several chronic diseases [2]. Public health guidelines for physical activity are that adults accumulate at least 150 minutes per week of moderate-to-vigorous intensity physical activity (MVPA) in bouts of 10 minutes or more [3-5]. This guideline is met by less than $15 \%$ of North American adults [6,7]. While sporadic physical activity (SPA), or physical activity occurring in periods of less than 10 consecutive minutes, is not recognized as providing health benefits within the current physical activity guidelines, a growing body of evidence suggests otherwise. Specifically, sporadic MVPA is associated with cardiometabolic risk factors independent of bouted

\footnotetext{
* Correspondence: ian.janssen@queensu.ca

'School of Kinesiology and Health Studies, Queen's University, Kingston, ON K7L 3N6, Canada

2Department of Public Health Sciences, Queen's University, Kingston, ON K7L ${ }^{2}$ Departmen
3N6, Canada
}

MVPA [8-10], and the associations between SPA and cardiometabolic risk factors are as strong as they are for bouted physical activity (BPA) [10]. Notable barriers to physical activity participation, including a lack of time and self-efficacy [11-13], may be less relevant for SPA than BPA.

Very little is known about how much SPA people accumulate. Data from a representative sample of adolescents [14] and a small convenience sample of older adults [15] suggest that approximately 66\% of MVPA occurs sporadically. However, the relative time spent engaging in moderate or vigorous intensity SPA is unknown. Additionally, no descriptive information exists about the amount of time spent engaging in light intensity SPA. There is a growing body of evidence indicating that light intensity physical activity provides health benefits independent of MVPA [16,17]. Thus, it is important to consider all movement intensities in studies of physical activity and not just MVPA. 
The purpose of this study is to describe SPA in adults. Specifically, this study describes how much daily SPA adults accumulate, the intensity at which it is accumulated, the contribution of SPA to total physical activity (ie, SPA + BPA), and whether these characteristics vary by sociodemographic factors. These results provide foundational knowledge that could be used to help design SPA interventions.

\section{Methods}

\section{Study design and participants}

Participants were from the 2003-2004 and 2005-2006 cycles of the U.S. National Health and Nutrition Examination Survey (NHANES), a nationally representative cross-sectional survey [18]. NHANES collects data through home interviews and physical examinations in mobile exam centers. All participants gave informed consent and NHANES was granted ethics approved by the National Center for Health Statistics.

The current study was limited to NHANES participants aged 20 years of age and older, non-pregnant women, and those who completed both the home interview and mobile exam center visit. This left an eligible sample of 9451. We excluded 3411 participants with missing or invalid physical activity accelerometer data (explained below), leaving a final sample of 6040 .

Potential selection bias arising from the lack of valid physical activity accelerometer data in 36\% of eligible participants was assessed by comparing several characteristics (sex, age, ethnicity, obesity) between the 6040 participants with valid data to the 3411 without. Differences were observed between the two samples for age, sex, and ethnicity but not for obesity. The age, sex, and racial differences were used to derive new sample weights to account for the selection bias.

\section{Sociodemographic variables}

Sociodemographic variables included sex, age (20-39 years old, 40-59 years old or 60+ years old), race/ethnicity (non-Hispanic white, non-Hispanic black, Mexican American or other) and body mass index (BMI) status (underweight $<18.5 \mathrm{~kg} / \mathrm{m}^{2}$, normal weight $18.5-24.9 \mathrm{~kg} /$ $\mathrm{m}^{2}$, overweight $25-29.9 \mathrm{~kg} / \mathrm{m}^{2}$, or obese $\geq 30 \mathrm{~kg} / \mathrm{m}^{2}$ [19]). BMI values were calculated from measured heights and weights.

\section{Physical activity}

SPA and BPA were assessed using Actigraph AM-7164 uniaxial accelerometers (Actigraph, Ft. Pensacola, FL). These accelerometers recorded average movement intensity, measured by counts in 1-minute intervals or epochs. Participants were given accelerometers at their mobile examination center visit and asked to wear them on an elasticized belt on their right hip for the 7 days after the visit. Participants were instructed to only remove the accelerometer when sleeping or when the accelerometer would get wet (e.g., bathing or swimming). After the 7 day measurement period was completed, participants mailed the accelerometers back to the NHANES researchers. The accelerometers were then tested to ensure calibration, the data were downloaded, and implausible count values were removed from the accelerometer database.

Further data reduction of the accelerometer database was carried out by the authors based on existing protocols [10,20-24]. Initially, we removed non-wear periods and calculated the wear time for each day. Non-wear periods were defined as periods with $\geq 90$ minutes of zero counts, with an allowance for 2 minutes of counts between 0 and 100 [22]. Next, each day was coded as valid or invalid and invalid days were removed from the dataset. Days were considered valid if the participant had $\geq$ 10 hours of wear time $[20,21,24]$. We then removed participants with 3 or fewer valid days [20,21,23,24].

After removing invalid days and participants with an insufficient number of valid days from the accelerometer database, each minute of physical activity data was categorized into one of four intensities based on established cut-points for the Actigraph AM-7164 accelerometer $[20,25]$. Specifically, values between 0-99 counts per minute were classified as sedentary, values between 100-2019 were classified as light intensity, values between 2020-5998 were classified as moderate intensity, and values $\geq 5999$ were classified as vigorous intensity. Data were then classified as being either BPA or SPA of different intensities, as explained in the following paragraph and as illustrated in Figure 1.

Initially, bouted MVPA was defined in the accelerometer database as periods of at least 10 consecutive minutes where the accelerometer counts exceeded the moderate threshold, with an allowance of $20 \%$ of the counts (e.g., 2 minutes for a 10 minute bout) being below the threshold $[9,10]$. Once the $20 \%$ threshold was surpassed, the bout was stopped. The time spent in bouted MVPA was summed, a daily average was created, and this information was exported into a new dataset. Bouted MVPA was then removed from the accelerometer database. Next, light intensity BPA was defined, in what remained of the accelerometer database, as periods of at least 10 consecutive minutes where the accelerometer counts exceeded the light intensity threshold, with an allowance of $20 \%$ of the counts being below the threshold. Once the 20\% threshold was surpassed, the bout was stopped. Note that light intensity BPA included MVPA, if the amount of MVPA did not satisfy the criteria for bouted MVPA. After light intensity BPA was counted, a daily average was created, and this information was exported into the new dataset. Light intensity 


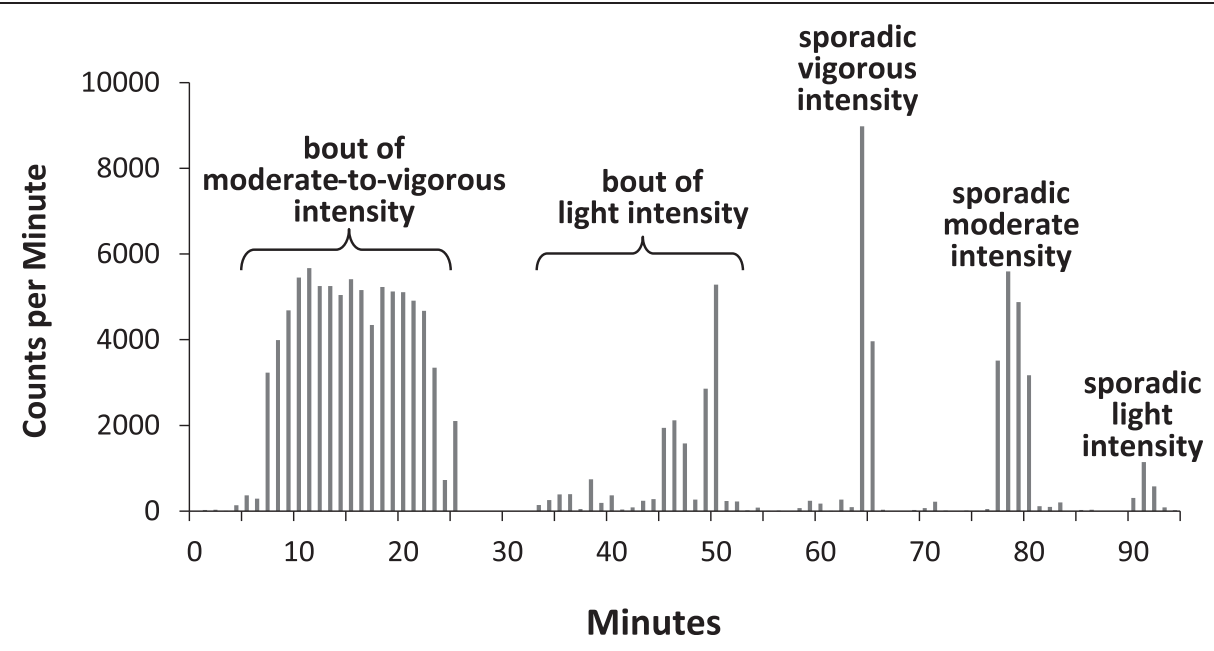

Figure 1 Classification of physical activity data from 95 minutes of accelerometer data obtained on a 24-year-old man.

BPA was then removed from the accelerometer database. At this phase, the accelerometer database only contained SPA and sedentary behavior. The daily averages for light intensity SPA, moderate intensity SPA, and vigorous intensity SPA were then calculated. These values were then exported in the new dataset. Total physical activity was then calculated in the new dataset as SPA + BPA. The new dataset was then merged with the other relevant NHANES datasets (eg, datasets that contained demographic information, BMI, etc.), and this merged dataset was use for the statistical analyses.

\section{Statistical analysis}

Analyses were conducted using SAS v9.3 (SAS Institute Inc., Cary, NC) and SPSS v22 (IBM Corporation, Armonk, $\mathrm{NY}$ ) and accounted for the clustered nature of NHANES and the adjusted sample weights that we created. Since the physical activity data were not normally distributed, we reported medians and interquartile ranges (IQR). Differences in median values across age, sex, ethnicity, and BMI groups were determined using Kruskal-Wallis omnibus and pairwise comparison tests. A p-value of $<$ 0.05 was used to denote statistical significance. Bonferroni adjusted p-values were used when there were multiple pairwise comparisons (ie, p .05/number of pairwise comparisons).

\section{Results}

A description of the sample is presented in Table 1. The majority of participants were between the ages of 20-30 and 40-59 years and of non-Hispanic white ethnicity. Approximately $32 \%$ were obese.

Median daily minutes of SPA in the total sample is shown in Table 2. American adults spent 103 minutes/ day (IQR: 85-121 minutes/day) engaging in SPA, which represented 27\% (IQR: 19-36\%) of their total (SPA + BPA) physical activity. The vast majority of SPA was of a light intensity (i.e., 100 of 103 minutes) and 91\% of participants accumulated no vigorous intensity SPA. Since almost all group comparisons were statistically significant, the statistical significance of these differences is not highlighted in the remainder of the Results.

Women accumulated slightly more SPA than men, both in minutes per day (105 vs. 101 minutes/day) and when expressed as a fraction of total physical activity (28 vs. $26 \%$ ). The median minute per day SPA values were 3 to 4 minutes lower in 20-39 year olds than in the older two age groups. However in $60+$ year olds, SPA as a fraction of total physical activity was 7 to 8 percentage points higher than in the two younger age groups. Mexican Americans spent 9 to 11 minutes/day less in SPA than non-Hispanic blacks and non-Hispanic whites. SPA did not differ in a meaningful way across normal weight, overweight, and obese groups; however, the underweight group accumulated 7 to 8 minutes/day more SPA than the other BMI groups. The age, race/ethnicity, and BMI patterns noted above were almost entirely attributable to differences in light intensity SPA. These patterns were also consistent when the sample was divided into men (Table 3) and women (Table 4).

Given the lack of moderate and vigorous intensity SPA, we decided a posteriori to investigate moderate and vigorous intensity activity embedded within light intensity BPA. This is hereafter referred to as embedded MVPA. Visual inspection of the accelerometer data revealed that many of the light intensity bouts contained some embedded MVPA (see Figure 1 for example). As shown in Table 5, the median value for embedded MVPA within the total sample was 16 minutes/day (IQR: 6-30 minutes/day). Men accumulated twice as 
Table 1 Characteristics of the study sample

\begin{tabular}{|c|c|c|c|c|c|c|}
\hline \multirow[b]{2}{*}{ Variable } & \multicolumn{2}{|c|}{ Total } & \multicolumn{2}{|c|}{ Men } & \multicolumn{2}{|c|}{ Women } \\
\hline & Crude N & Weighted \% (SE) & Crude N & Weighted \% (SE) & Crude N & Weighted \% (SE) \\
\hline \multicolumn{7}{|l|}{ Age } \\
\hline 20-39 years & 1672 & $37.3(1.1)$ & 904 & $39.8(1.5)$ & 768 & $35.0(1.2)$ \\
\hline $40-59$ years & 1968 & $39.4(1.0)$ & 976 & $39.4(1.3)$ & 992 & $39.5(1.2)$ \\
\hline$\geq 60$ years & 2400 & $23.3(1.0)$ & 1209 & $20.9(1.1)$ & 1191 & $25.5(1.2)$ \\
\hline \multicolumn{7}{|l|}{ Race/Ethnicity } \\
\hline Non-Hispanic white & 3241 & $72.2(2.3)$ & 1666 & $72.3(2.3)$ & 1575 & $72.1(2.4)$ \\
\hline Non-Hispanic black & 1169 & $11.3(1.4)$ & 581 & $10.5(1.3)$ & 588 & $12.0(1.5)$ \\
\hline Mexican American & 1226 & $7.7(1.1)$ & 650 & $8.6(1.2)$ & 576 & $6.8(1.8)$ \\
\hline Other & 404 & $8.8(0.8)$ & 192 & $8.6(0.9)$ & 212 & $9.1(0.9)$ \\
\hline \multicolumn{7}{|l|}{ Body Mass Index } \\
\hline$<18.5 \mathrm{~kg} / \mathrm{m}^{2}$ & 131 & $2.3(0.2)$ & 63 & $2.1(0.3)$ & 68 & $2.6(0.3)$ \\
\hline $18.5-24.9 \mathrm{~kg} / \mathrm{m}^{2}$ & 1767 & $31.8(0.9)$ & 826 & $26.7(1.3)$ & 941 & $36.6(1.5)$ \\
\hline $25-29.9 \mathrm{~kg} / \mathrm{m}^{2}$ & 2163 & $34.1(0.9)$ & 1283 & $40.3(1.2)$ & 880 & $28.1(1.1)$ \\
\hline$\geq 30 \mathrm{~kg} / \mathrm{m}^{2}$ & 1979 & $31.9(1.1)$ & 917 & $30.9(1.5)$ & 1062 & $32.8(1.2)$ \\
\hline
\end{tabular}

much embedded MVPA as women (20 vs. 10 minutes/ day) and 20-39 year olds accumulated more embedded MVPA than 40-59 year olds and 60+ year olds. NonHispanic blacks accumulated the least amount of embedded MVPA. Median embedded MVPA values were 5 to 8 minutes/day higher in the normal weight and overweight groups than in the underweight and obese groups.

\section{Discussion}

This representative sample of American adults spent 103 minutes/day engaging in SPA of any intensity, which represented $27 \%$ of their total (SPA + BPA) physical activity. Only 3 minutes/day of the SPA was of a moderate-to-vigorous intensity; however, the sample accumulated another 16 minutes/day of MVPA embedded within bouts of primarily light intensity activity. Although there were statistically significant differences in SPA across age, sex, ethnicity and BMI groups; these differences were small and primarily due to light intensity SPA.

Our finding that moderate-to-vigorous SPA represents $13 \%$ of total MVPA in American adults is lower than what has been reported previously. Within the Third Generation Cohort of the Framingham Heart Study, mean sporadic MVPA was 19 minutes/day, which represented 68\% of total MVPA time [9]. Within a representative sample of Canadian adults, sporadic MVPA accounted for $53 \%$ of total MVPA energy expenditure [10]. In a representative sample of youth [14] and a small convenience sample of older adults [15] sporadic MVPA accounted for $66 \%$ of total MVPA time. The difference between our findings and previous findings is likely explained in large measure by differences in how SPA was classified. Specifically, in previous studies all MVPA occurring outside of bouted MVPA was considered sporadic. Conversely, in our study we calculated two forms of non-bouted physical MVPA; MVPA that was truly sporadic and MVPA that was embedded within bouts of primarily light intensity activity. While the truly sporadic MVPA only accounted for 2 minutes/day or $13 \%$ of total MVPA, the truly sporadic and embedded MVPA combined accounted for 17 minutes/day or $98 \%$ of total MVPA in the typical participant.

We feel that it is important to differentiate between MVPA that is truly sporadic and MVPA that is embedded within bouts of primarily light intensity activity as they may influence health differently and act through different biological mechanisms. True SPA may play a role in breaking up extended sedentary periods. Recent studies have shown that the frequency of breaks in sedentary periods is associated with cardiometabolic risk factors [25-27]. Conversely, MVPA embedded within light intensity bouts may impact health primarily by increasing energy expenditure. As the majority of American adults do not engage in sports $[28,29]$ that are known to contain a mixture of different movement intensities [30], it is likely that a major source of embedded MVPA in adults is through occupational activity. For example, a farmer may spend a large amount of time in light intensity activity walking around the farm then perform short bursts of higher intensity activity in the form of animal tending or hay bailing. 
Table 2 Median (interquartile range) daily time spent in sporadic physical activity of different intensities, in minutes per day and as a fraction of total of sporadic physical activity, within the total sample and according to sex, age, race/ethnicity, and body mass index

\begin{tabular}{|c|c|c|c|c|c|c|c|c|}
\hline & \multicolumn{4}{|c|}{ Minutes per day } & \multicolumn{4}{|c|}{ Fraction of total physical activity } \\
\hline & Light intensity & Moderate intensity & Vigorous intensity & All intensities & Light intensity & Moderate intensity & Vigorous intensity & All intensities \\
\hline Total sample & $100.4(82.8-117.8)$ & $2.1(1.1-3.6)$ & $0(0-0)$ & $103.0(85.4-120.8)$ & $26.1(18.2-34.8)$ & $0.5(0.3-0.9)$ & $0(0-0)$ & $26.9(18.8-35.7)$ \\
\hline \multicolumn{9}{|l|}{ Sex } \\
\hline Men & $97.6(79.8-114.5)$ & $2.6(1.4-4.5)$ & $0(0-0)$ & $100.9(82.7-118.3)$ & $24.7(16.8-34.0)$ & $0.6(0.4-1.1)$ & $0(0-0)$ & $25.6(17.4-35.2)$ \\
\hline Women & $102.9(86.0-121.0)$ & $1.6(0.9-2.8)$ & $0(0-0)$ & $105.2(88.6-124.1)$ & $27.3(19.6-35.5)$ & $0.4(0.2-0.7)$ & $0(0-0)$ & $27.7(20.0-36.2)$ \\
\hline \multicolumn{9}{|l|}{ Age } \\
\hline 20-39 years & $97.6(78.3-114.8)$ & $2.8(1.7-4.6)$ & $0(0-0)$ & $100.9(81.7-118.4)$ & $23.4(15.7-31.6)$ & $0.7(0.4-1.3)$ & $0(0-0)$ & $24.3(16.3-32.9)$ \\
\hline $40-59$ years & $101.4(84.5-119.8)$ & $2.3(1.3-3.6)$ & $0(0-0)$ & $104.5(87.2-123.5)$ & $25.1(18.1-33.0)$ & $0.5(0.3-0.9)$ & $0(0-0)$ & $25.9(18.6-34.0)$ \\
\hline$\geq 60$ years & $102.3(87.3-119.1)$ & $0.9(0.5-1.6)$ & $0(0-0)$ & $103.7(88.4-120.5)$ & $32.0(23.8-44.4)$ & $0.3(0.2-0.5)$ & $0(0-0)$ & $32.6(24.2-44.9)$ \\
\hline \multicolumn{9}{|l|}{ Race/Ethnicity } \\
\hline Non-Hispanic white & $100.6(83.8-117.7)$ & $2.0(1.0-3.7)$ & $0(0-0)$ & $103.4(86.4-120.7)$ & $26.7(19.0-35.3)$ & $0.5(0.3-0.9)$ & $0(0-0)$ & $27.4(19.6-36.2)$ \\
\hline Non-Hispanic black & $102.8(84.8-120.1)$ & $2.0(1.2-3.3)$ & $0(0-0)$ & $105.3(87.4-123.1)$ & $25.8(18.3-34.8)$ & $0.5(0.3-0.8)$ & $0(0-0)$ & $26.4(18.8-35.7)$ \\
\hline Mexican American & $92.0(69.1-111.9)$ & $2.2(1.3-3.6)$ & $0(0-0)$ & $94.6(71.7-115.9)$ & $19.9(12.7-29.7)$ & $0.5(0.3-0.8)$ & $0(0-0)$ & $20.6(13.1-30.6)$ \\
\hline Other & $101.4(80.8-122.9)$ & $2.2(1.3-3.5)$ & $0(0-0)$ & $104.4(84.8-125.7)$ & $26.3(16.7-35.6)$ & $0.5(0.3-0.9)$ & $0(0-0)$ & $26.9(17.1-36.5)$ \\
\hline \multicolumn{9}{|l|}{ Body Mass Index } \\
\hline$<18.5 \mathrm{~kg} / \mathrm{m}^{2}$ & $107.8(84.6-121.7)$ & $2.2(1.2-4.4)$ & $0(0-0)$ & $110.4(90.7-126.4)$ & $30.2(21.9-41.3)$ & $0.7(0.4-1.1)$ & $0(0-0)$ & $31.3(22.6-43.1)$ \\
\hline $18.5-24.9 \mathrm{~kg} / \mathrm{m}^{2}$ & $100.7(82.6-119.0)$ & $2.3(1.2-3.9)$ & $0(0-0)$ & $103.3(85.6-122.0)$ & $25.4(17.4-33.4)$ & $0.5(0.3-0.9)$ & $0(0-0)$ & $26.3(18.1-34.5)$ \\
\hline $25-29.9 \mathrm{~kg} / \mathrm{m}^{2}$ & $100.0(83.3-117.2)$ & $2.1(1.0-3.7)$ & $0(0-0)$ & $103.0(86.2-120.8)$ & $25.8(18.2-34.3)$ & $0.5(0.3-0.9)$ & $0(0-0)$ & $26.4(18.7-35.5)$ \\
\hline$\geq 30 \mathrm{~kg} / \mathrm{m}^{2}$ & $99.5(82.3-116.8)$ & $1.9(1.1-3.2)$ & $0(0-0)$ & $102.2(84.4-119.6)$ & $26.7(18.8-36.4)$ & $0.5(0.3-0.8)$ & $0(0-0)$ & $27.4(19.2-37.3)$ \\
\hline
\end{tabular}


Table 3 Median (interquartile range) daily time spent in sporadic physical activity of different intensities, in minutes per day and as a fraction of total physical activity, within men and according to sex, age, race/ethnicity, and body mass index

\begin{tabular}{|c|c|c|c|c|c|c|c|c|}
\hline & \multicolumn{4}{|c|}{ Minutes per day } & \multicolumn{4}{|c|}{ Fraction of total physical activity (SPA + BPA) } \\
\hline & Light intensity & Moderate intensity & Vigorous intensity & All intensities & Light intensity & Moderate intensity & Vigorous intensity & All intensities \\
\hline All Men & $97.6(79.8-114.5)$ & $2.6(1.4-4.5)$ & $0(0-0)$ & $100.9(82.7-118.3)$ & $24.7(16.8-34.0)$ & $0.6(0.4-1.1)$ & $0(0-0)$ & $25.6(17.4-35.2)$ \\
\hline \multicolumn{9}{|l|}{ Age } \\
\hline 20-39 years & $93.4(72.6-110.7)$ & $3.4(2.0-5.3)$ & $0(0-0)$ & $97.9(76.8-115.8)$ & $21.4(13.8-30.0)$ & $0.8(0.4-1.3)$ & $0(0-0)$ & $22.2(14.3-31.1)$ \\
\hline $40-59$ years & $99.5(80.8-116.6)$ & $2.8(1.8-4.6)$ & $0(0-0)$ & $102.9(83.8-121.2)$ & $24.2(16.8-32.6)$ & $0.7(0.4-1.2)$ & $0(0-0)$ & $25.0(17.5-33.8)$ \\
\hline$\geq 60$ years & $101.3(86.1-117.1)$ & $1.3(0.6-2.0)$ & $0(0-0)$ & $103.0(87.5-118.9)$ & $31.7(24.2-44.5)$ & $0.4(0.2-0.7)$ & $0(0-0)$ & $32.3(24.7-45.1)$ \\
\hline \multicolumn{9}{|l|}{ Race/Ethnicity } \\
\hline Non-Hispanic white & $98.4(81.6-114.7)$ & $2.5(1.4-4.5)$ & $0(0-0)$ & $101.5(84.2-118.3)$ & $25.7(17.6-34.8)$ & $0.6(0.4-1.1)$ & $0(0-0)$ & 26.7 (18.4-36.0) \\
\hline Non-Hispanic black & $100.8(83.8-118.7)$ & $2.5(1.5-4.2)$ & $0(0-0)$ & $103.9(86.8-120.7)$ & $23.5(17.2-32.3)$ & $0.6(0.3-1.0)$ & $0(0-0)$ & $24.4(17.6-33.4)$ \\
\hline Mexican American & $82.0(61.2-105.2)$ & $2.7(1.6-4.0)$ & $0(0-0)$ & $86.2(64.9-108.1)$ & $17.1(10.8-25.8)$ & $0.5(0.3-0.8)$ & $0(0-0)$ & $17.7(11.3-26.6)$ \\
\hline Other & $97.5(76.5-115.9)$ & $3.0(1.9-4.7)$ & $0(0-0)$ & $102.1(78.7-121.0)$ & $24.9(14.9-36.5)$ & $0.7(0.4-1.3)$ & $0(0-0)$ & $25.9(16.1-37.5)$ \\
\hline \multicolumn{9}{|l|}{ Body Mass Index } \\
\hline$<18.5 \mathrm{~kg} / \mathrm{m}^{2}$ & $109.8(81.4-122.7)$ & $2.8(1.5-4.6)$ & $0(0-0)$ & $114.0(82.9-127.1)$ & $30.3(20.8-40.9)$ & $0.8(0.5-1.1)$ & $0(0-0)$ & $31.3(21.6-42.7)$ \\
\hline $18.5-24.9 \mathrm{~kg} / \mathrm{m}^{2}$ & $98.2(78.8-114.6)$ & $2.9(1.6-4.8)$ & $0(0-0)$ & $101.3(83.0-117.7)$ & $23.4(15.6-33.1)$ & $0.7(0.4-1.1)$ & $0(0-0)$ & $24.3(16.5-34.4)$ \\
\hline $25-29.9 \mathrm{~kg} / \mathrm{m}^{2}$ & $97.5(80.8-114.5)$ & $2.6(1.4-4.5)$ & $0(0-0)$ & $100.8(83.4-119.0)$ & $24.4(16.8-32.9)$ & $0.6(0.4-1.1)$ & $0(0-0)$ & $25.4(17.4-34.2)$ \\
\hline$\geq 30 \mathrm{~kg} / \mathrm{m}^{2}$ & $97.2(79.1-113.8)$ & $2.4(1.4-4.0)$ & $0(0-0)$ & $100.3(81.7-117.3)$ & $25.6(17.5-35.6)$ & $0.6(0.3-1.1)$ & $0(0-0)$ & $26.4(18.3-36.7)$ \\
\hline
\end{tabular}

Note: All group comparisons were statistically significant. 
Table 4 Median (interquartile range) daily time spent in sporadic physical activity of different intensities, in minutes per day and as a fraction of total physical activity, within women and according to sex, age, race/ethnicity, and body mass index

\begin{tabular}{|c|c|c|c|c|c|c|c|c|}
\hline & \multicolumn{4}{|c|}{ Minutes per day } & \multicolumn{4}{|c|}{ Fraction of total physical activity } \\
\hline & Light intensity & Moderate intensity & Vigorous intensity & All intensities & Light intensity & Moderate intensity & Vigorous intensity & All intensities \\
\hline All Women & $102.9(86.0-121.0)$ & $1.6(0.9-2.8)$ & $0(0-0)$ & $105.2(88.6-124.1)$ & $27.3(19.6-35.5)$ & $0.4(0.2-0.7)$ & $0(0-0)$ & $27.7(20.0-36.2)$ \\
\hline \multicolumn{9}{|l|}{ Age } \\
\hline 20-39 years & $102.0(83.8-119.2)$ & $2.4(1.4-3.9)$ & $0(0-0)$ & $104.6(86.2-122.7)$ & $25.7(17.7-33.0)$ & $0.6(0.3-1.0)$ & $0(0-0)$ & $26.6(18.4-33.8)$ \\
\hline $40-59$ years & $103.4(87.0-123.1)$ & $1.8(1.1-2.8)$ & $0(0-0)$ & $105.6(89.4-126.3)$ & $25.7(19.0-33.4)$ & $0.4(0.3-0.7)$ & $0(0-0)$ & $26.5(19.4-34.2)$ \\
\hline$\geq 60$ years & $103.6(88.1-120.2)$ & $0.8(0.4-1.3)$ & $0(0-0)$ & $104.7(89.1-121.4)$ & $32.4(23.5-44.3)$ & $0.2(0.1-0.5)$ & $0(0-0)$ & $32.7(23.7-44.6)$ \\
\hline \multicolumn{9}{|l|}{ Race/Ethnicity } \\
\hline Non-Hispanic white & $102.8(86.4-120.6)$ & $1.6(0.8-2.9)$ & $0(0-0)$ & $105.0(89.3-123.1)$ & $27.5(20.1-35.6)$ & $0.4(0.2-0.7)$ & $0(0-0)$ & $28.2(20.6-36.2)$ \\
\hline Non-Hispanic black & $104.1(86.0-121.0)$ & $1.6(0.9-2.6)$ & $0(0-0)$ & $106.7(88.2-124.7)$ & $27.0(19.8-35.9)$ & $0.4(0.2-0.7)$ & $0(0-0)$ & $27.6(20.1-36.7)$ \\
\hline Mexican American & 98.1 (79.8-118.5) & $1.7(1.0-2.7)$ & $0(0-0)$ & $100.1(82.0-120.9)$ & $24.5(16.2-32.5)$ & $0.4(0.2-0.7)$ & $0(0-0)$ & $25.0(16.6-33.7)$ \\
\hline Other & $104.6(85.6-126.8)$ & $1.7(1.0-2.6)$ & $0(0-0)$ & $105.9(87.3-129.6)$ & $26.7(17.1-34.5)$ & $0.4(0.3-0.6)$ & $0(0-0)$ & $27.1(17.3-35.5)$ \\
\hline \multicolumn{9}{|l|}{ Body Mass Index } \\
\hline$<18.5 \mathrm{~kg} / \mathrm{m}^{2}$ & $106.1(85.5-121.1)$ & $2.0(1.0-3.6)$ & $0(0-0)$ & $108.3(90.9-125.6)$ & $29.8(22.8-42.3)$ & $0.6(0.3-1.0)$ & $0(0-0)$ & $31.1(23.0-43.0)$ \\
\hline $18.5-24.9 \mathrm{~kg} / \mathrm{m}^{2}$ & $102.1(85.2-121.6)$ & $1.8(0.9-3.0)$ & $0(0-0)$ & $104.7(87.6-125.3)$ & $26.7(19.1-33.7)$ & $0.4(0.2-0.8)$ & $0(0-0)$ & $27.3(19.5-34.5)$ \\
\hline $25-29.9 \mathrm{~kg} / \mathrm{m}^{2}$ & $103.6(88.7-122.2)$ & $1.4(0.8-2.6)$ & $0(0-0)$ & $106.0(90.2-124.1)$ & $27.1(19.4-35.9)$ & $0.4(0.2-0.7)$ & $0(0-0)$ & $27.7(19.9-36.7)$ \\
\hline$\geq 30 \mathrm{~kg} / \mathrm{m}^{2}$ & $102.9(85.8-119.2)$ & $1.6(0.9-2.6)$ & $0(0-0)$ & $104.6(87.5-121.2)$ & $27.9(19.9-36.8)$ & $0.4(0.3-0.7)$ & $0(0-0)$ & $28.6(20.3-37.4)$ \\
\hline
\end{tabular}

$\geq 30 \mathrm{~kg} / \mathrm{m}^{2}$ groups. 
Table 5 Median (interquartile range) minutes per day spent in moderate-to- vigorous intensity physical activity embedded within bouts of light intensity physical activity within the total sample and according to sex, age, race/ethnicity, and body mass index

\begin{tabular}{|c|c|c|c|}
\hline & Moderate intensity & Vigorous intensity & Moderate-to-vigorous intensity \\
\hline Total Sample & $14.4(5.2-28.5)$ & $0.0(0.0-0.2)$ & $15.5(5.7-29.7)$ \\
\hline \multicolumn{4}{|l|}{ Sex } \\
\hline Men & $19.8(8.3-36.2)$ & $0.0(0.0-0.4)$ & $20.3(8.5-38.2)$ \\
\hline Women & $9.7(3.3-20.8)$ & $0.0(0.0-0.0)$ & $9.8(3.4-22.0)$ \\
\hline \multicolumn{4}{|l|}{ Age } \\
\hline 20-39 years & $20.5(10.3-34.5)$ & $0.0(0.0-0.7)$ & $21.2(10.8-37.0)$ \\
\hline 40-59 years & $15.4(6.5-28.8)$ & $0.0(0.0-0.2)$ & $15.9(6.7-29.7)$ \\
\hline$\geq 60$ years & $3.3(0.7-11.4)$ & $0.0(0.0-0.0)$ & $3.3(0.7-11.4)$ \\
\hline \multicolumn{4}{|l|}{ Race/Ethnicity } \\
\hline Non-Hispanic white & $14.0(4.7-28.0)^{a}$ & $0.0(0.0-0.2)^{a}$ & $14.6(4.8-29.4)^{a}$ \\
\hline Non-Hispanic black & $12.6(4.8-26.2)^{a}$ & $0.0(0.0-0.2)^{a}$ & $12.7(4.9-27.6)^{a}$ \\
\hline Mexican American & $18.8(8.4-37.0)^{b}$ & $0.0(0.0-0.3)^{a}$ & $19.2(8.5-38.0)^{b}$ \\
\hline Other & $15.1(6.6-29.0)^{b}$ & $0.0(0.0-0.2)^{a}$ & $15.3(6.7-30.7)^{b}$ \\
\hline \multicolumn{4}{|l|}{ Body Mass Index } \\
\hline$<18.5 \mathrm{~kg} / \mathrm{m}^{2}$ & $12.0(4.8-23.5)^{a}$ & $0.0(0.0-0.2)^{a b}$ & $12.2(4.8-24.0)^{a}$ \\
\hline $18.5-24.9 \mathrm{~kg} / \mathrm{m}^{2}$ & $17.1(6.6-33.2)^{b}$ & $0.0(0.0-0.6)^{b}$ & $18.3(6.8-35.3)^{b}$ \\
\hline $25-29.9 \mathrm{~kg} / \mathrm{m}^{2}$ & $16.0(5.8-29.7)^{b}$ & $0.0(0.0-0.2)^{a}$ & $16.7(5.9-30.9)^{b}$ \\
\hline$\geq 30 \mathrm{~kg} \mathrm{~kg} / \mathrm{m}^{2}$ & $10.2(3.5-21.7)^{a}$ & $0.0(0.0-0.0)^{a}$ & $10.3(3.5-22)^{a}$ \\
\hline
\end{tabular}

Note: All group comparisons were statistically significant unless the median (interquartile range) is followed by an ${ }^{\mathrm{a}}$ or ${ }^{\mathrm{b}}$ symbol. Groups with the same letter symbols were not statistically different from each other.

It is encouraging that the typical American adult accumulates 17 minutes/day of non-bouted MVPA, particularly given that they spend an average of $<10 \mathrm{~min} /$ day in bouted MVPA [20], a volume of MVPA that falls well below that recommended for good health [3-5]. Non-bouted or SPA may also represent another intervention opportunity. SPA may be easier to intervene upon in populations without the free time to participate in BPA. That is, it may be easier for people to add a few minutes of physical activity here and there throughout the day rather than devoting a single longer block of time (eg, 30 minutes) to getting their activity. Also, SPA may provide an intervention opportunity for people who do not have the confidence or belief in their ability to participate in extended BPA. Doing a little bit of activity here and there may be perceived as being easier and less intimidating than bouts of activity. SPA based interventions also may have potential for greater maintenance of physical activity behavior post intervention, which is a known problem for BPA interventions [31].

Key limitations of this study warrant recognition. The physical activity patterns observed in this sample from 2003-2006 may not represent current behavior. While accelerometers provide an objective measure of physical activity, they are not without fault. They do not accurately capture activities that are not step based (i.e. cycling, swimming, upper body activities), and the accelerometers used in NHANES were uniaxial and primarily captured horizontal movement at the hip. Nonetheless, we feel that a vast majority of physical activity was captured since walking is the most common form of leisure-time physical activity [32] and is heavily involved in occupational and transportation activities. Conversely, less than 2\% of Americans engage in strength training and cycling [28].

\section{Conclusion}

SPA of any intensity accounted for $27 \%$ of total daily physical activity in Americans adults. Sporadic MVPA and MVPA embedded within light intensity bouts accounted for $98 \%$ of total MVPA. Future research is needed to better understand the types of activity that represent embedded MVPA patterns, and to investigate if sporadic MVPA and embedded MVPA have a different impact on health outcomes.

Competing interests

The authors declare that they have no competing interests. 


\section{Authors' contributions}

JR and IJ contributed to the study concept and design. JR was responsible for the data management, statistical analysis, and wrote the first draft of the manuscript. IJ provided advice on the data management, statistical analysis, and interpretation of the data and critically revised the manuscript. Both of the authors approved the final version of the manuscript submitted for publication.

\section{Acknowledgements}

Funding for this project was provided by the Heart and Stroke Foundation of Ontario. IJ was supported by a Canada Research Chair award.

Received: 2 October 2014 Accepted: 5 January 2015

Published: 10 January 2015

\section{References}

1. Brownson RC, Boehmer TK, Luke DA. Declining rates of physical activity in the United States: what are the contributors? Annu Rev Public Health. 2005;26:421-43.

2. Warburton DE, Nicol CW, Bredin SS. Health benefits of physical activity: the evidence. CMAJ. 2006;174(6):801-9.

3. Tremblay MS, Warburton DE, Janssen I, Paterson DH, Latimer AE, Rhodes RE, et al. New Canadian physical activity guidelines. Appl Physiol Nutr Metab. 2011:36(1):36-46

4. Haskell WL, Lee IM, Pate RR, Powell KE, Blair SN, Franklin BA, et al. Physical activity and public health: updated recommendation for adults from the American College of Sports Medicine and the American Heart Association. Med Sci Sports Exerc. 2007;39(8):1423-34.

5. World Health Organization. Global recommendations on physical activity for health. Geneva, Switzerland: World Health Organization; 2010.

6. Colley RC, Garriguet D, Janssen I, Craig CL, Clarke J, Tremblay MS. Physical activity of Canadian adults: accelerometer results from the 2007 to 2009 Canadian Health Measures Survey. Health Rep. 2011:22(1):7-14.

7. Tucker JM, Welk GJ, Beyler NK. Physical activity in U.S.: adults compliance with the Physical Activity Guidelines for Americans. Am J Prev Med. 2011:40(4):454-61.

8. Strath SJ, Holleman RG, Ronis DL, Swartz AM, Richardson CR. Objective physical activity accumulation in bouts and nonbouts and relation to markers of obesity in US adults. Prev Chronic Dis. 2008;5(4):A131.

9. Glazer NL, Lyass A, Esliger DW, Blease SJ, Freedson PS, Massaro JM, et al. Sustained and shorter bouts of physical activity are related to cardiovascular health. Med Sci Sports Exerc. 2013;45(1):109-15.

10. Clarke J, Janssen I. Sporadic and Bouted Physical Activity and the Metabolic Syndrome in Adults. Med Sci Sports Exerc. 2014;46(1):76-83.

11. Bergman P, Grjibovski AM, Hagstromer M, Bauman A, Sjostrom M. Adherence to physical activity recommendations and the influence of socio-demographic correlates - a population-based cross-sectional study. BMC Public Health. 2008;8:367.

12. Bauman AE, Reis RS, Sallis JF, Wells JC, Loos RJ, Martin BW. Lancet Physical Activity Series Working G: Correlates of physical activity: why are some people physically active and others not? Lancet. 2012;380(9838):258-71.

13. Trost SG, Owen N, Bauman AE, Sallis JF, Brown W. Correlates of adults' participation in physical activity: review and update. Med Sci Sports Exerc. 2002;34(12):1996-2001

14. Mark $A E$, Janssen I. Influence of bouts of physical activity on overweight in youth. Am J Prev Med. 2009;36(5):416-21.

15. Copeland $J \mathrm{~L}$, Esliger DW. Accelerometer assessment of physical activity in active, healthy older adults. J Aging Phys Act. 2009;17(1):17-30.

16. Healy GN, Dunstan DW, Salmon J, Cerin E, Shaw JE, Zimmet PZ, et al. Objectively measured light-intensity physical activity is independently associated with 2-h plasma glucose. Diabetes Care. 2007;30(6):1384-9.

17. Katzmarzyk PT. Standing and mortality in a prospective cohort of Canadian adults. Med Sci Sports Exerc. 2014;46(5):940-6.

18. National Health and Nutrition Examination Survey Data. 2003-2006. http://www.cdc.gov/nchs/nhanes/nhanes_questionnaires.htm.

19. World Health Organization. Obesity: preventing and managing the global epidemic. Report of a WHO consultation. World Health Organ Tech Rep Ser. 2000;894:1-253.

20. Troiano RP, Berrigan D, Dodd KW, Masse LC, Tilert T, McDowell M. Physical activity in the United States measured by accelerometer. Med Sci Sports Exerc. 2008:40(1):181-8
21. Colley R, Connor Gorber S, Tremblay MS. Quality control and data reduction procedures for accelerometry-derived measures of physical activity. Health Rep. 2010;21(1):63-9.

22. Choi L, Liu Z, Matthews CE, Buchowski MS Validation of accelerometer wear and nonwear time classification algorithm. Med Sci Sports Exerc. 2011:43(2):357-64.

23. Trost SG, Mclver KL, Pate RR. Conducting accelerometer-based activity assessments in field-based research. Med Sci Sports Exerc. 2005;37(11 Suppl):S531-43.

24. Masse LC, Fuemmeler BF, Anderson CB, Matthews CE, Trost SG, Catellier DJ, et al. Accelerometer data reduction: a comparison of four reduction algorithms on select outcome variables. Med Sci Sports Exerc. 2005;37(11 Suppl):S544-54

25. Healy GN, Dunstan DW, Salmon J, Cerin E, Shaw JE, Zimmet PZ, et al. Breaks in sedentary time: beneficial associations with metabolic risk. Diabetes Care. 2008;31(4):661-6.

26. Bankoski A, Harris TB, McClain JJ, Brychta RJ, Caserotti P, Chen KY, et al. Sedentary activity associated with metabolic syndrome independent of physical activity. Diabetes Care. 2011;34(2):497-503

27. Carson V, Wong SL, Winkler E, Healy GN, Colley RC, Tremblay MS. Patterns of sedentary time and cardiometabolic risk among Canadian adults. Prev Med. 2014:65C:23-7.

28. Tudor-Locke C, Johnson WD, Katzmarzyk PT. Frequently reported activities by intensity for U.S. adults: the American Time Use Survey. Am J Prev Med 2011. 2010;41(2):238-8

29. Ham SA, Kruger J, Tudor-Locke C. Participation by US adults in sports, exercise, and recreational physical activities. J Phys Act Health. 2009;6(1):6-14.

30. Guagliano JM, Rosenkranz RR, Kolt GS. Girls' physical activity levels during organized sports in Australia. Med Sci Sports Exerc. 2013;45(1):116-22.

31. Fjeldsoe B, Neuhaus M, Winkler E, Eakin E. Systematic review of maintenance of behavior change following physical activity and dietary interventions. Health Psychol. 2011;30(1):99-109.

32. Siegel PZ, Brackbill RM, Heath GW. The epidemiology of walking for exercise: implications for promoting activity among sedentary groups. Am J Public Health. 1995:85(5):706-10.

doi:10.1186/2052-1847-7-2

Cite this article as: Robson and Janssen: A description of the volume and intensity of sporadic physical activity among adults. BMC Sports Science, Medicine, and Rehabilitation 2015 7:2

\section{Submit your next manuscript to BioMed Central and take full advantage of:}

- Convenient online submission

- Thorough peer review

- No space constraints or color figure charges

- Immediate publication on acceptance

- Inclusion in PubMed, CAS, Scopus and Google Scholar

- Research which is freely available for redistribution 